\title{
ENTRE LA ONTOLOGÍA HEIDEGGERIANA Y LA MARXIANA. H. MARCUSE Y SU INTERPRETACIÓN DE LOS MANUSCRITOS PARISINOS DE MARX
}

Jordi Magnet Colomer Universidad de Barcelona (UB) jordi.magnet@gmail.com

Recepción: 8 de agosto de 2016 Aceptación: 24 de agosto de 2016 


\section{RESUMEN}

El presente artículo aborda la recepción de los Manuscritos de economía y filosofía (1844) de K. Marx en la obra de H. Marcuse. En sus ensayos «Nuevas fuentes para la fundamentación del materialismo histórico» (1932) y «Sobre los fundamentos filosóficos del concepto científico-económico de trabajo» (1933), Marcuse empieza a tomar distancia respecto de su anterior pretensión de hallar un soporte ontológico para el materialismo histórico, recurriendo exclusivamente a la fenomenología existencial de Heidegger. A partir de la primera publicación de los Manuscritos de economía y filosofía en 1932, el autor berlinés buscará fundamentar ontológicamente el materialismo histórico con el recurso a la obra juvenil de Marx.

\section{Palabras Clave}

Herbert Marcuse, Martin Heidegger, Karl Marx, ontología, trabajo.

\section{ABSTRACT}

This article deals with the reception of Marx's Economic and Philosophic Manuscripts (1844) in H. Marcuse's work. In his essays «New Sources on the Foundation of Historical Materialism» (1932) and «On the Philosophical Foundation of the Concept of Labor in Economics» (1933), Marcuse distances himself from his previous attempt to find an ontological basis for Historical Materialism using only Heidegger's Existential Phenomenology. Since the first publication of Economic and Philosophic Manuscripts in 1932, the Berliner author will seek to base Historical Materialism ontologically drawing on Marx's early work.

\section{Keywords}

Herbert Marcuse, Martin Heidegger, Karl Marx, Ontology, Labor. 


\title{
ENTRE LA ONTOLOGÍA HEIDEGGERIANA Y LA MARXIANA. H. MARCUSE Y SU INTERPRETACIÓN DE LOS MANUSCRITOS PARISINOS DE MARX
}

\author{
Jordi Magnet Colomer \\ Universidad de Barcelona (UB) \\ jordi.magnet@gmail.com
}

\section{Introducción}

Siendo asistente de M. Heidegger en la Universidad de Freiburg, entre 1929 y 1932, el primer Marcuse se aventuró a interpretar ontológicamente algunos pasajes de La ideología alemana (1845) y de los Grundrisse (1857) de Marx, sin conocer todavía los Manuscritos de economía y filosofia (1844). ${ }^{1}$

\footnotetext{
${ }^{1}$ Se refiere explícitamente a las nociones empleadas por Marx de Daseinformen ("formas de existencia») y Existenzbestimmungen ("determinaciones de la existencia»). El concepto de existencia histórico-universal, empleado en La ideología alemana, haría referencia (hace referencia) según Marcuse, a la existencia propia o auténtica del Dasein. Como esta existencia posee un carácter ontológico, que la hace ser «verdadera» «frente a todas las desviaciones fácticas», a ojos del joven Marcuse se volvía (se vuelve) prioritario para la crítica de estas desviaciones (es decir, para el marxismo) el desvelamiento de esa estructura ontológica fundamental con ayuda del análisis fenomenológico. Sobre esto véase $\mathrm{H}$. Marcuse, "Contribuciones a una fenomenología del materialismo histórico", en J. M. Romero (ed.). H. Marcuse y los orígenes de la teoría crítica (Madrid: Plaza y Valdés, 2010), 88. (H. Marcuse, «Beiträge zu einer Phänomenologie des Historischen Materialismus», Schriften Vol. 1 (Frankfurt am Main: Suhrkamp, 1978), 352) y H. Marcuse , «El problema de la realidad histórica», en Id. Entre hermenéntica y teoría crítica. Artículos 1929-1931 (Barcelona: Herder, 2011), 147. (H. Marcuse, «Das Problem der geschichtlichen Wirklichkeit», Schriften Vol. 1., 480).
} 
Pero tal empresa tenía un corto recorrido, puesto que, en términos generales, Marcuse advertía un claro déficit ontológico en el materialismo histórico. Esta carencia debía suplirse con el recurso a la ontología fundamental de Ser y tiempo (1927) y a su concepto de historicidad (Geschichtlichkeit). Sin embargo, una vez hubo leído los cuadernos de París de Marx en 1932, Marcuse encontró en los análisis sobre el trabajo alienado la fundamentación ontológica que hasta entonces había estando buscando en Heidegger. El autor berlinés desmiente que a partir de 1932 todavía estuviera intentando movilizar el marco ontológico de Ser y tiempo con fines marxistas. Frente al persistente interés de Habermas en este punto, Marcuse niega que en la interpretación que hiciera de los Manuscritos de economía y filosofía de Marx, la ontología de Heidegger tuviera peso alguno. El predominio de un afán ontológico en sus análisis no era ya legado de Heidegger sino de una ontología que creyó "poder descubrir en el propio Marx». ${ }^{2}$ Del mismo modo, en el marxismo de Lukács y Korsch, a quienes Marcuse asegura haber leído antes que a Heidegger, se encuentra algo más que «una estrategia y una fijación de objetivos políticos», a saber, una ontología «que remite a un fundamento ontológico más o menos implícito en la obra de Marx». ${ }^{3}$

La versión que ofrece Marcuse en su conversación con Habermas ha sido desacreditada por diversos intérpretes, quienes se han obstinado en resaltar que en sus artículos, de 1932 y 1933, el joven Marcuse aún no se había librado tanto como desearía del influjo de Heidegger. ${ }^{4}$ Como veremos a continuación, si bien es indudable que en estos escritos persiste algo del ímpetu ontológico que recibiera de Ser y tiempo, la ontología que esgrime ahora Marcuse -ciertamente «fundamental» pero también materialista y dia-

\footnotetext{
2 J. Habermas et al., Conversaciones con Herbert Marcuse (Barcelona: Gedisa, 1980), 14.

${ }^{3}$ J. Habermas et al., Conversaciones con Herbert Marcuse, 15.

${ }^{4}$ Cfr. D. Kellner, Herbert Marcuse and the Crisis of Marxism (Los Angeles: University of California Press, 1984), 88; T. McCarthy, "Heidegger y la teoría crítica: el primer encuentro», en Ideales e ilusiones: reconstrucción y deconstrucción en la teoría crítica contemporánea (Madrid: Tecnos, 1992), 103; J. M. Romero, «¿Entre Marx y Heidegger? La trayectoria filosófica del primer Marcuse» en H. Marcuse, Entre hermenéutica y teoría crítica. Artículos 1929-1931, 20; R. Wolin, «Herbert Marcuse: del marxismo existencial al heideggerianismo de izquierdas», en Los hijos de Heidegger (Madrid: Cátedra, 2003), 230.
} 
léctica-, solo puede derivarse tangencialmente de la ontología fundamental de Heidegger. Lo que ocurre es que se tiende a atribuir a esa ontología una ascendencia heideggeriana más pronunciada de lo que en realidad es, porque los críticos afrontan estos textos demasiado condicionados por el trasfondo filosófico de sus primeros artículos de la etapa comprendida entre 1928 y 1932. Y, en efecto, en ellos el joven Marcuse hizo pivotar toda su investigación sobre la base de la ontología de Ser y Tiempo y de su concepto de historicidad. Parece entonces que todo planteamiento ontológico ulterior del joven Marcuse tuviera aún que proceder forzosamente de Heidegger. No obstante, en el seno de la filosofia marxista otros autores desarrollaron, a lo largo de las décadas siguientes, planteamientos ontológicos análogos a los de Marcuse, y no por esto vino a imputárseles una influencia externa procedente de la ontología heideggeriana o existencial, sino que desde un principio se vio ese desarrollo ontológico como una interpretación inmanente a los escritos del joven Marx. Baste citar como ejemplo los trabajos elaborados por la Escuela de Budapest, que básicamente continuaron el proyecto de la «ontología del ser social» del último Lukács. ${ }^{5}$ Pues bien, los comentarios sobre los Manuscritos de Marcuse presentan, por lo general, más puntos en común con esa suerte de ontología social derivada íntegramente de Marx que con la ontología fundamental de Heidegger. A grandes rasgos, en el pormenorizado análisis que hace el joven Marcuse de los Manuscritos de economía y filosofía marxianos de 1844, en la extensa reseña «Nuevas fuentes para la fundamentación del materialismo histórico» (1932) y en el artículo «Sobre los fundamentos filosóficos del concepto científico-económico de trabajo» (1933), sobresalen al menos tres ejes temáticos interconectados que habremos de desarrollar con detenimiento. El primero de ellos, central para nuestro propósito de determinar en qué grado la ontología fundamental de Ser y tiempo sigue gozando o no de un lugar privilegiado en estos escritos, es dirimir si la lectura ontológica de los Manuscritos que nos propone el autor

\footnotetext{
${ }^{5}$ Gyorgy Markús y la primera Ágnes Heller desarrollaron una antropología social marxista ontológicamente fundamentada en los escritos juveniles de Marx. Cfr. G. Markus, Marxismo y antropología (Barcelona: Grijalbo, 1974) y A. Heller, Hipótesis para una teoría marxista de los valores (Barcelona: Grijalbo, 1973).
} 
berlinés puede derivarse en su totalidad del propio Marx o si, por el contrario, Marcuse prosigue en lo esencial la tarea de explicitar las estructuras fundamentales de la existencia y la realidad humana con el recurso a una fenomenología dialéctica de la historicidad de procedencia heideggeriana (1). De otra parte, ahondaremos en la crítica de Marx y Marcuse al antropologismo de la "esencia humana» (Menschenwesen) de Feuerbach, con el objeto de contrarrestar algunos de los ataques que se le han formulado a Marcuse (2). Abordaremos, por último, la centralidad ontológica del concepto de trabajo en Marcuse, cuyo alcance no ha sido siempre bien comprendido por sus críticos (3).

\section{La lectura marcuseana de los Manuscritos de París de Marx}

Según el discurso económico predominante - proceda este de la teoría burguesa o del marxismo clásico-, el concepto de trabajo equivale a la praxis en la dimensión económica. Su sistemático y erróneo emplazamiento en esta dimensión «ha influido (...) decisivamente en las interpretaciones de la esencia del trabajo en cuanto tal, también fuera de la esfera económica». ${ }^{6} \mathrm{~A}$ este concepto reduccionista de trabajo, opone Marcuse un concepto ontológico que apunta directamente al modo de acontecer propio del ser humano. Para llegar a inferir los caracteres fundamentales de la esencia ontológica del trabajo, como el modo específico de acontecer del ser humano en el mundo, Marcuse somete a una reducción fenomenológica el concepto económico y cotidiano de trabajo. ${ }^{7}$ En su definición ontológica del trabajo, va a aglutinar lo primordial de tres tradiciones: la esencia del trabajo como un «hacer» (Hegel), la concepción del trabajo como praxis en tanto que autoproducción y

\footnotetext{
${ }^{6} \mathrm{H}$. Marcuse, «Sobre los fundamentos filosóficos del concepto científico-económico de trabajo", en Id., Sobre Marx y Heidegger. Escritos filosóficos (1932-1933) (Madrid: Biblioteca Nueva, 2016), 124. (H. Marcuse, Über die philosophischen Grundlagen des wirtschaftswissenschaftlichen Arbeitsbegriffs, Schriften Vol. 1, 557).

${ }^{7}$ R. Wolin, «Herbert Marcuse: del marxismo existencial al heideggerianismo de izquierdas», en Los hijos de Heidegger, 231.
} 
autorrealización de sí mismo en la objetivación (el joven Marx) y la estructura praxeológica del ser del Dasein como «cuidado» (Sorge) (Heidegger).

Al estar cada vez más apegado a la tradición hegeliano-marxista, en su definición ontológica del trabajo, Marcuse reúne tanto el momento subjetivo y ontológico autoconstitutivo como el momento objetivo de «mediación» y «objetivación» en la constitución del mundo histórico-social. Algo ciertamente impensable en la caracterización de la situacionalidad práctica del Dasein en Ser y tiempo, donde el acontecer del Dasein en el mundo circundante como Sorge -nunca como trabajo- queda al margen de toda objetivación.

La atención prestada al proceso de objetivación corrobora que la ontología que está manejando en este momento Marcuse ya no proviene exclusivamente de Heidegger. El concepto de «sensibilidad» como objetivación práctico-social -que se remonta a Kant y llega hasta Feuerbach y Marx- es para Marcuse la categoría que fundamenta el materialismo y un elemento central en la definición de la esencia del hombre. ${ }^{8} \mathrm{Al}$ incorporar la objetivación a la esencia del ser humano, y situar las categorías ontológicas -como ya hiciera en "Contribuciones a una fenomenología del materialismo histórico» (1928) y en «Sobre filosofia concreta» (1929)- en la situación histórico-concreta, Marcuse toma distancia de la ontología fundamental de Ser y tiempo. Aunque, a decir verdad, eso no impida que siga haciendo un uso más o menos sistemático del lenguaje de la ontología tradicional. Por lo demás, si en «Contribuciones a una fenomenología del materialismo histórico» Marcuse interpretaba de modo materialista la Sorge heideggeriana, ubicándola en el ámbito de la producción y reproducción material y espiritual de la realidad para la satisfacción de las necesidades existenciales del Dasein ${ }^{9}$, en «Sobre los fundamentos filosóficos del concepto científico-económico del

\footnotetext{
${ }^{8}$ H. Marcuse, «Nuevas fuentes para la fundamentación del materialismo histórico», en Id., Sobre Marx y Heidegger. Escritos filosóficos (1932-1933), 84-86. (H. Marcuse, Neue Quellen zur Grundlegung des Historischen Materialismus, Schriften Vol. 1., 525-528).

${ }^{9}$ H. Marcuse, "Contribuciones a una fenomenología del materialismo histórico», en J. M. Romero (ed.). H. Marcuse y los orígenes de la teoría crítica, 116, 117, 121. (H. Marcuse, «Beiträge zu einer Phänomenologie des Historischen Materialismus», Schriften Vol. 1., 374, 375, 378).
} 
trabajo» (1933) esa función productiva y reproductiva ya no es encomendada a la Sorge sino al «trabajo» (Arbeit).

Pero Marcuse continúa confiriendo a la dimensión ontológica del trabajo unas características muy similares a las que otorgó anteriormente al ámbito de la historicidad, siendo ambas condiciones estructurantes de la existencia humana independientes «de todas las formas sociales». ${ }^{10}$ En consecuencia, sus correspondientes plasmaciones fácticas, en la dimensión histórico-social respectiva, serán más o menos adecuadas según realicen (en el comunismo positivo), contradigan o inviertan (en las sociedades capitalistas fundadas en la propiedad privada y el trabajo enajenado) los caracteres fundamentales de esa dimensión esencial. Si en «Contribuciones a una fenomenología del materialismo histórico» el baremo ontológico-normativo para enjuiciar la facticidad era el concepto de historicidad, en «Sobre los fundamentos filosóficos del concepto científico-económico del trabajo» ese baremo lo ocupa el concepto ontológico de trabajo. Pero no es de por sí el intento de elucidar «los caracteres concretos del trabajo» «dentro de una ontología del hombre» ${ }^{11}$ lo que aproxima decisivamente la interpretación marcuseana de los Manuscritos a Heidegger, ya que lo mismo podría decirse acerca de la proximidad de Marcuse con el joven Marx; es más bien en la sobrestimación de la dimensión ontológica en el proceso de trabajo donde puede apreciarse, con más nitidez, la supeditación de Marcuse a una generalización ontológica que recuerda a la de Heidegger en Ser $y$ tiempo. ${ }^{12}$

Puesto que Marcuse carga el acento en la elucidación ontológica del trabajo como el «carácter del acontecer del ser humano en el que se efectúa la autorealización de su modo propio de ser» ${ }^{13}$, el análisis socioeconómico para determinar si tal acontecer ontológico-esencial del ser hu-

\footnotetext{
${ }^{10} \mathrm{H}$. Marcuse, «Sobre los fundamentos filosóficos del concepto científico-económico de trabajo", en Id., Sobre Marx y Heidegger. Escritos filosóficos (1932-1933), 130. (H. Marcuse, Über die philosophischen Grundlagen des wirtschaftswissenschaftlichen Arbeitsbegriffs, Schriften Vol. 1., 561).

11 H. Marcuse, «Sobre los fundamentos filosóficos del concepto científico-económico de trabajo», en Id., Sobre Marx y Heidegger. Escritos filosóficos (1932-1933), 147. (H. Marcuse, Über die philosophischen Grundlagen des wirtschaftswissenschaftlichen Arbeitsbegriffs, Schriften Vol. 1., 575).

${ }^{12}$ D. Kellner, Herbert Marcuse and the Crisis of Marxism, 83 y 89.

${ }^{13}$ J. M. Romero, «¿Entre Marx y Heidegger? La trayectoria filosófica del primer Marcuse» en H. Marcuse. Entre hermenéutica y teoría crítica. Artículos 1929-1931, 20.
} 
mano se realiza adecuadamente o no, en las circunstancias históricas actuales, parece ocupar un plano más bien secundario en su estudio.

En comparación con sus anteriores artículos, en la reseña de los Manuscritos, Marcuse no concede tanto protagonismo al concepto de historicidad de Ser y tiempo. Sin embargo, es sacado a colación en un momento decisivo de la exposición, a saber, cuando se clarifica la comprensión de la dialéctica entre «esencia» y «facticidad». Como es sabido, en las condiciones históricas del capitalismo el tránsito socio-económico es regulado mediante la propiedad privada y el trabajo enajenado. El sujeto debe venderse a sí mismo como fuerza de trabajo mercantilizada y, de este modo, su actividad ontológica propia, esto es, el trabajo como forma de acontecer esencial de su ser, deviene en un mero medio para la simple supervivencia, para la conservación de la existencia. Si el trabajo es ontológicamente el modo propio de autorrealización y exteriorización del ser humano en el mundo, el trabajo enajenado supone una desrealización y alienación totales del ser humano. La situación fáctica del capitalismo invierte y encubre, pues, la esencia del ser humano y del trabajo humano es ser libre. ${ }^{14}$ Así, desde el punto de vista de la historia de la esencia del hombre, la situación histórica concreta del capitalismo -sea este liberal o monopolístico- representa la «inversión del mundo humano socio-histórico en un mundo extraño de dinero y mercancías, contrapuesto a los hombres como poder hostil» ${ }^{15}$; la objetivación se trueca en cosificación y la exteriorización en enajenación. Dado que el ser humano se desempeña como trabajador abstracto, «arrancado de la realidad de la existencia (Dasein) humana» ${ }^{16}$, esta inversión sacude también la existencia entera del ser humano.

\footnotetext{
${ }^{14}$ H. Marcuse, "Nuevas fuentes para la fundamentación del materialismo histórico», en Id., Sobre Marx y Heidegger. Escritos filosóficos (1932-1933), 96. (H. Marcuse, Neue Quellen zur Grundlegung des Historischen Materialismus, Schriften Vol. 1., 533).

${ }^{15}$ H. Marcuse, «Nuevas fuentes para la fundamentación del materialismo histórico», en Id., Sobre Marx y Heidegger. Escritos filosóficos (1932-1933), 69. (H. Marcuse, Neue Quellen zur Grundlegung des Historischen Materialismus, Schriften Vol. 1., 512).

${ }^{16}$ H. Marcuse, "Nuevas fuentes para la fundamentación del materialismo histórico», en Id., Sobre Marx y Heidegger. Escritos filosóficos (1932-1933), 69. (H. Marcuse, Neue Quellen zur Grundlegung des Historischen Materialismus, Schriften Vol. 1., 512).
} 
A diferencia de lo que creían algunos jóvenes hegelianos, la crítica no debe aspirar a invertir simplemente esta realidad, a fin de que la existencia se convierta en un medio para la realización de la esencia. La praxis revolucionaria persigue la supresión de la dicotomía entre esencia y existencia como regiones independientes entre sí y la cancelación radical de la facticidad que invierte la esencia humana. ${ }^{17} \mathrm{Y}$ como esta facticidad supone una auténtica "catástrofe del ser humano» ${ }^{18}$ no basta con reformar los niveles políticos y económicos de la sociedad; se precisa de una «revolución total» ${ }^{19}$. A juicio de Marcuse, el reconocimiento de la historicidad como determinación esencial -junto a la aprehensión de los caracteres ontológicos del trabajo libre-, no permite identificar, en el estado actual, la historia esencial del hombre con su historia fáctica ${ }^{20}$. Es decir, en última instancia es el nivel ontológico de la historicidad, y del acontecer de esta historicidad como un «hacer» ontológico-dinámico a través del trabajo humano, aquello que sirve para sentenciar la facticidad histórica del capitalismo. En este aspecto, Marcuse continúa amarrado a una concepción ontológica similar a la de sus primeros artículos; es decir, concibe la dimensión ontológica como esencial y normativa.

\section{Sobre la historicidad del concepto de esencia humana}

Paradójicamente, el concepto ontológico de historicidad sirve a Marcuse para ponernos sobre aviso y no malinterpretar la dimensión esen-

\footnotetext{
${ }^{17} \mathrm{H}$. Marcuse, «Nuevas fuentes para la fundamentación del materialismo histórico», en $I d$., Sobre Marx y Heidegger. Escritos filosóficos (1932-1933), 98. (H. Marcuse, Neue Quellen zur Grundlegung des Historischen Materialismus», Schriften Vol. 1., 536).

${ }^{18} \mathrm{H}$. Marcuse, «Nuevas fuentes para la fundamentación del materialismo histórico», en Id., Sobre Marx y Heidegger. Escritos filosóficos (1932-1933), 99. (H. Marcuse, Neue Quellen zur Grundlegung des Historischen Materialismu», Schriften Vol. 1., 536).

${ }^{19} \mathrm{H}$. Marcuse, «Nuevas fuentes para la fundamentación del materialismo histórico», en Id., Sobre Marx y Heidegger. Escritos filosóficos (1932-1933), 99. (H. Marcuse, Neue Quellen zur Grundlegung des Historischen Materialismus, Schriften Vol. 1., 536).

${ }^{20} \mathrm{H}$. Marcuse, "Nuevas fuentes para la fundamentación del materialismo histórico», en $I d$., Sobre Marx y Heidegger. Escritos filosóficos (1932-1933), 98. (H. Marcuse, Neue Quellen zur Grundlegung des Historischen Materialismus, Schriften Vol. 1., 536).
} 
cial como haciendo alusión a una esencia humana abstracta y transhistórica ${ }^{21}$. Aquí Marcuse apela a la historicidad heideggeriana para insuflar mayor consistencia a la crítica de Marx al antropologismo de Feuerbach ${ }^{22}$. La esencia humana es «el conjunto de las relaciones sociales»" ${ }^{23}$, determinada históricamente por un modo de producción específico, que es el contenido material de esa historicidad. El punto de Arquímedes de la crítica del joven Marx y de Marcuse a la sociedad capitalista no es, pues, una esencia humana inmutable que debiera contraponerse y terminar imponiéndose a la facticidad de la situación histórica. El basamento de esa crítica es la imposibilidad fáctica de realizar las necesidades y potencialidades humanas -ambas productos de la historia de la humanidad- en las condiciones históricas de la sociedad capitalista ${ }^{24}$. Lo que la praxis revolucionaria debe suprimir es el antagonismo entre potencialidad y realidad condicionado por el modo de producción.

Es conocido que el antropologismo naturalista de Feuerbach emerge en el contexto de la crítica de la izquierda hegeliana a la filosofia idealista y especulativa de Hegel. El concepto de «esencia genérica» (Gattungswesen) desciende en él desde el reino teológico hasta una base terrenal. De entre todos los hegelianos de izquierda, Feuerbach destaca por haber llevado a cabo la primera inversión materialista, filosóficamente decisiva pero insuficiente, de la concepción idealista de la alienación (Entfremdung) como enajenación de la conciencia (Hegel). De acuerdo a La esencia del cristianismo (1841), lo que se enajena no es la conciencia en toda objetivación, es decir, en el con-

\footnotetext{
${ }^{21}$ H. Marcuse, "Nuevas fuentes para la fundamentación del materialismo histórico», en Id., Sobre Marx y Heidegger. Escritos filosóficos (1932-1933), 98. (H. Marcuse, Neue Quellen zur Grundlegung des Historischen Materialismus, Schriften Vol. 1., 535).

${ }^{22}$ Lo paradójico es cómo el concepto ontológico de historicidad, entendiendo por tal las condiciones ontológico-transcendentales de posibilidad de la historia fáctica y de su conocimiento, puede ser comprendido de otra forma que no sea en términos de una esencia humana abstracta y transhistórica, pues la historicidad no es en sí misma histórica y no depende en absoluto de las condiciones históricas concretas y fácticas en las que se realiza en cada caso. Parece, pues, que Marcuse toma ya aquí la historicidad en una acepción más óntica que ontológica, lo que le distancia sin duda de Heidegger.

${ }^{23}$ K. Marx, "Ad Feuerbach», en La ideología alemana (I) y otros escritos filosóficos (Buenos Aires: Losada, 2010), 17.

${ }^{24}$ D. Kellner, Herbert Marcuse and the Crisis of Marxism, 81, 82, 84.
} 
junto de productos objetivos y de cosas creadas por el ser humano, sino la «esencia humana» (Menschenwesen) en la atribución de sus potencialidades a formas externas -como sería el caso de la religión- que arrancan al ser humano de sí mismo esclavizándolo a sus propias creaciones ${ }^{25}$. Donde Hegel creía divisar en la religión una forma -aunque no la más elevada- de alcanzar el Espíritu conciencia de sí mismo, Feuerbach no veía más que alienaciones de la «esencia genérica».

Durante el período que media entre su etapa como demócrata revolucionario y redactor de la Gaceta renana (Rheinische Zeitung) hasta la publicación de las Tesis sobre Feuerbach ${ }^{26}$, aproximadamente entre 1842 y 1845, el joven Marx se halla bajo el influjo de una concepción filosófica fundamentalmente feuerbachiana. Cierto es que la ruptura de Marx con la izquierda hegeliana se inicia ya con la Crítica de la filosofía del derecho de Hegel (1843), pero el antropologismo naturalista de Feuerbach tendrá cierta continuidad en los Manuscritos de economía y filosofía (1844). Por lo pronto, la prolongación de la crítica de Feuerbach a Hegel presenta en Marx una acepción positiva y otra negativa. Por una parte, le permite profundizar en una dirección precisa y acorde a sus tempranas aspiraciones políticas la crítica a la filosofia especulativa de Hegel. Pero, por otra parte, el joven Marx se verá inevitablemente condicionado -confrontándose a ello con nuevas formulaciones conceptuales- por el problemático repliegue de la crítica hacia la reivindicación de una «esencia humana» que Feuerbach tiende a concebir como invariable a través de las distintas formaciones sociales concretas de la historia y, también en parte, independiente de ellas. Tras rendir cuentas con la actitud teórica y contemplativa de Feuerbach en las célebres Tesis de 1845, la abstracción universalizante del Gattungswesen feuerbachiano será abandonada de modo definitivo y contundente por Marx en La ideología alemana (1845), donde ya en el prólogo el lenguaje filosófico de la «esencia del hombre» (Wesen des Mensches) de Feuerbach y de todos los demás jóvenes hegelianos es vilipen-

\footnotetext{
${ }^{25}$ Cfr. L. Feuerbach, «La esencia de la religión», en La esencia del cristianismo (Barcelona: Círculo de Lectores, 1996), 86-108.

${ }^{26}$ Para una aproximación concisa a lo esencial de esa recepción véase: I. Monal «Ser genérico, esencia genérica en el joven Marx», Crítica Marxista, n 16, (2003): 96-108.
} 
diado y tratado sin miramientos en cuanto "fantasías inocentes y pueriles» ${ }^{27}$ ligadas todavía a la filosofia idealista y a la mistificación hegelianas.

Ya el hecho de que el joven Marcuse fuera el primer autor marxista en llevar a cabo un minucioso comentario de los Manuscritos, apenas unos meses después de haber sido publicados, valorando positivamente su aparición como un «acontecimiento decisivo en la historia de la investigación sobre Marx» ${ }^{28}$, deja entrever cuán lejos se encontraban sus inclinaciones teóricas de las del marxismo oficial de los partidos. En líneas generales, todas las tendencias cientificistas y revisionistas del momento tendieron a mostrar escaso interés por esta obra central del período juvenil de Marx, al juzgar sus contenidos como supeditados a una herencia hegeliana que habría sido desmantelada progresivamente por Marx, para dar nacimiento a la teoría propiamente científica y materialista de la sociedad. Sin embargo, en la misma medida en que Marcuse se alejaba de la ortodoxia marxista, tampoco quedó aferrado a una interpretación de los Manuscritos que desembocara en un humanismo abstracto -en realidad más próximo a Feuerbach que a Marx-, en la que indudablemente sucumbieron no pocos -humanistas marxistas- en décadas posteriores ${ }^{29}$.

En opinión de Habermas, la producción teórica de Marcuse posee una «impronta fuertemente antropológica» ${ }^{30}$. Sin cuestionar la validez de este juicio, que ciertamente puede ratificarse a lo largo de toda su obra, no deja de resultar excesiva la afirmación de A. Sánchez Vázquez, según la cual Marcuse habría llevado a cabo una «interpretación antropológica absoluta» ${ }^{31}$

\footnotetext{
${ }^{27}$ K. Marx, La ideología alemana (I) y otros escritos filosóficos, 23.

${ }^{28}$ H. Marcuse, «Nuevas fuentes para la fundamentación del materialismo histórico», en Id., Sobre Marx y Heidegger. Escritos filosóficos (1932-1933), 65. (H. Marcuse, Neue Quellen zur Grundlegung des Historischen Materialismus, Schriften Vol. 1., 509).

${ }^{29} \mathrm{Al}$ entronizar en exceso el lado «humanista» de la teoría de Marx, se corre el riesgo de estar más cercano a Feuerbach que al propio Marx. Las propuestas de un «humanismo marxista» radical son a menudo intercambiables a las de la izquierda hegeliana. En este sentido, Althusser indicaba incluso que algunos marxistas humanistas adjudicaban equivocadamente al joven Marx afirmaciones que no eran sino citas que este había tomado de Feuerbach para someterlas a discusión. Véase L. Althusser, La revolución teórica de Marx (México: Siglo XXI, 2004), 43.

${ }^{30}$ J. Habermas et al., Conversaciones con Herbert Marcuse, 30.

${ }^{31}$ A. Sánchez Vázquez, El joven Marx. Los Manuscritos de 1844 (México: UNAM, 2003), 259.
} 
de los Manuscritos y que, de acuerdo a esta interpretación, «el joven Marx no habría rebasado el antropologismo de Feuerbach $»^{32}$. Contrariamente a lo que defiende SánchezVázquez -y aquí su crítica tiende a coincidir con la del marxismo-leninismo ${ }^{33}$-, la «revolución total» que Marcuse invoca siguiendo al joven Marx no es solamente una revolución antropológica. Como ya hemos argumentado, la supresión de la cosificación y de la alienación no está fundada en un humanismo abstracto ni en una teoría antropológica idéntica a la de Feuerbach. Ahora bien, respecto al hegelianismo de Marcuse, Sánchez Vázquez sí acierta cuando sostiene que el autor berlinés sitúa de lleno la problemática presentada en los Manuscritos en el marco de la filosofia hegeliana, haciendo extensivo dicho enmarcamiento al resto de su obra ${ }^{34}$.

\section{El debate sobre la ontología del trabajo}

La ontología del trabajo que despliega Marcuse en estos ensayos ha sido también discutida desde otros frentes. Douglas Kellner hace hincapié en la nociva influencia que ejercen el idealismo alemán y la fenomenología existencial de Heidegger en la determinación marcuseana de los caracteres del trabajo ${ }^{35}$. Estos caracteres son la «duración o continuidad», la «constancia» (el trabajo como hacer que se objetiva) y el «carácter de carga». Por el contrario, el juego es discontinuo, no se objetiva y, al no estar sometido a la «ley de la cosa», está libre de toda carga. Según Kellner, en la dicotomía que Marcuse establece entre el «reino de la necesidad» y el «reino de la libertad», donde el trabajo como «carga» queda supuestamente fuera del ámbito de la realización óptima de las potencialidades del sujeto, sería detectable aquella

\footnotetext{
32 A. Sánchez Vázquez, El joven Marx. Los Manuscritos de 1844, 262.

33 Cfr. R. Steigerwald, Herbert Marcuses dritter Weg (Köln: Pahl-Rugenstein, 1969), 102.

${ }^{34}$ A. Sánchez Vázquez, El joven Marx. Los Manuscritos de 1844, 262. En los Manuscritos se encontrarían ya reunidas «todas las categorías conocidas de la posterior crítica de la economía política» (H, Marcuse, «Nuevas fuentes para la fundamentación del materialismo histórico», en Id., Sobre Marx y Heidegger. Escritos filosóficos (1932-1933), 66). (H. Marcuse, Neue Quellen zur Grundlegung des Historischen Materialismus, Schriften Vol. 1., 509).

${ }^{35}$ D. Kellner, Herbert Marcuse and the Crisis of Marxism, 89.
} 
concepción de la libertad incondicionada del sí-mismo procedente del idealismo alemán y del existencialismo ${ }^{36}$.

Pero el planteamiento de Marcuse alberga una complejidad mayor que no se corresponde al modo como lo presenta Kellner en su crítica. Cuando alude al carácter de carga del trabajo, Marcuse está haciendo mención a un rasgo estructural de la existencia misma del ser humano. A diferencia del animal, el ser humano no puede «dejar-acontecer» su existencia en el mundo de forma inmediata. «El hombre se encuentra permanentemente con una situación de su sí mismo y de su mundo que no es inmediatamente la suya propia, de manera que pudiera dejar-acontecer simplemente su existencia (Dasein) en esa inmediatez; él debe primeramente hacer suya cada situación 'mediándola' consigo»" ${ }^{37}$. Impulsado por esta situación de carencia o insuficiencia original, el trabajo como «hacer-acontecer» está condicionado inherentemente por la «necesidad». Dicha necesidad nunca puede colmarse; es una necesidad de la existencia en sí misma, la cual, en contra de lo que suponen ingenuamente las teorías de corte economicista, no se satisface con el mero acopio de bienes. Naturalmente, ese carácter de carga, intrínseco a la propia estructura del ser del sujeto, se ve incrementado exponencialmente por determinadas formas de organización social del trabajo. En contextos de servidumbre, la entera praxis de la existencia queda circunscrita a la esfera de la producción y reproducción material «al servicio y bajo la dirección de otra existencia (Dasein) (precisamente, de la 'dominante') y sus demandas» ${ }^{38}$. Es verdad, como señala Kellner, que Marcuse fracciona el mundo de la existencia histórica en dos esferas («reino de la necesidad» $\mathrm{y}$ «reino de la libertad»), pero es falso que el trabajo en su totalidad se vea relegado por él a la esfera de la «necesidad». Kellner no interpreta correctamente la dialéctica de «libertad» y «necesidad» en la ontología del trabajo de Marcuse. Si el mundo

\footnotetext{
${ }^{36}$ D. Kellner, Herbert Marcuse and the Crisis of Marxism, 90.

${ }^{37}$ H. Marcuse, «Sobre los fundamentos filosóficos del concepto científico-económico de trabajo», en Id., Sobre Marx y Heidegger. Escritos filosóficos (1932-1933), 139. (H. Marcuse, Über die philosophischen Grundlagen des wirtschaftswissenschaftlichen Arbeitsbegriffs, Schriften Vol. 1., 569). ${ }^{38}$ H. Marcuse, «Sobre los fundamentos filosóficos del concepto científico-económico de trabajo", en Id., Sobre Marx y Heidegger. Escritos filosóficos (1932-1933), 167. (H. Marcuse, Über die philosophischen Grundlagen des wirtschaftswissenschaftlichen Arbeitsbegriffs, Schriften Vol. 1., 591).
} 
de la existencia histórica es efectivamente separado en dos reinos, el concepto "general» de trabajo engloba dos polaridades complementarias: el haceracontecer supeditado a la producción y reproducción material para cubrir las simples necesidades de la existencia (necesidad) y el hacer-acontecer más allá de estas necesidades (libertad). Ambos modos de acontecer pertenecen a la esencia del trabajo. Pero en aquellas sociedades donde prevalece el trabajo enajenado, el hacer-acontecer se vincula en su conjunto a la dimensión económica de la «necesidad». Se produce entonces la fragmentación de esa «bidimensionalidad en la totalidad de la existencia» en una «bidimensionalidad de diferentes totalidades de existencia»" Solo en este caso "cae toda la carga y fatiga del trabajo (en la medida en que se fundan precisamente en la objetividad del trabajo) en la dimensión de la producción y reproducción materiales, en la praxis de lo necesario», quedando adscrita a determinados niveles y clases socio-económicas (principalmente al proletariado), «mientras que simultáneamente la dimensión de la libertad conforme a la existencia (daseinsmäßig) es separada y descargada de esa praxis» ${ }^{40}$. En clara discordancia con lo que asevera Kellner, Marcuse se muestra contrario a disociar el trabajo como producción y reproducción material de las dimensiones de la 'libertad' que la completan y consuman ${ }^{41}$. Si restringiera el perímetro de la comprensión del fenómeno del trabajo en su vertiente productiva y reproductiva, Marcuse estaría certificando y universalizando teóricamente -con pretensiones transhistóricas- una realidad cosificada y cosificante que forma parte de las condiciones del trabajo enajenado en las sociedades capitalistas.

\footnotetext{
${ }^{39}$ H. Marcuse, «Sobre los fundamentos filosóficos del concepto científico-económico de trabajo", en Id., Sobre Marx y Heidegger. Escritos filosóficos (1932-1933), 169. (H. Marcuse, Über die philosophischen Grundlagen des wirtschaftswissenschaftlichen Arbeitsbegriffs, Schriften Vol. 1., 593).

${ }^{40} \mathrm{H}$. Marcuse, «Sobre los fundamentos filosóficos del concepto científico-económico de trabajo", en Id., Sobre Marx y Heidegger. Escritos filosóficos (1932-1933), 169. (H. Marcuse, Über die philosophischen Grundlagen des wirtschaftswissenschaftlichen Arbeitsbegriffs, Schriften Vol. 1., 593). ${ }^{41} \mathrm{H}$. Marcuse, «Sobre los fundamentos filosóficos del concepto científico-económico de trabajo", en Id., Sobre Marx y Heidegger. Escritos filosóficos (1932-1933), 170-171. (H. Marcuse, Über die philosophischen Grundlagen des wirtschaftswissenschaftlichen Arbeitsbegriffs, Schriften Vol. 1., 593).
} 
El segundo frente crítico, que vino a cuestionar la unidimensionalidad de la ontología del trabajo marxiana, se materializó en una profunda renovación del marco categorial del materialismo histórico que hizo tambalear los patrones interpretativos (trabajo, objetivación, etc.) en los que se habían respaldado tradicionalmente las corrientes filosóficas del marxismo occidental y del humanismo marxista. Habermas fue el principal artífice del viraje efectuado en el seno de la tradición de la Teoría Crítica desde el paradigma de la producción-trabajo al paradigma lingüístico-comunicativo. La alteración del orden de prioridades analíticas, consolidado por la segunda generación de la Escuela de Frankfurt, se tradujo en una sustitución de la «crítica de la economía política» por la «teoría de la acción comunicativa». El diagnóstico que avaló este "giro» objetaba que dentro del paradigma de la producción-trabajo -paradigma al que también pertenece el razonamiento de Marcuse-, la dimensión simbólica y comunicativa de la existencia humana (en la que cabría incluir las «relaciones de producción») pierde significancia o bien queda subsumida dentro del modelo reduccionista de la dimensión tecnológico-instrumental (el ámbito de las «fuerzas productivas») $)^{42}$. Así, mientras el paradigma de la producción-trabajo entiende la autorrealización del ser humano solamente a través del trabajo (Arbeit), el paradigma comunicativo-lingüístico subraya un modo alternativo de autorrealización y autoproducción, a saber, la interacción social mediada simbólicamente (fundamentalmente a través del lenguaje). Sin embargo, es esta una interpretación cuestionable, susceptible de ser rebatida desde distintos ángulos. Considerado en su globalidad, el planteamiento de Habermas achaca injustamente a Marx una visión en exceso productivista y, por ende, un culto desmesurado a las fuerzas productivas. El concepto marxiano de trabajo se entiende como actividad instrumental, en su aspecto meramente productivista. Pero es precisamente el principio de valorización por el que se rige el trabajo en las sociedades capitalistas -en tanto que producción por la producción- contra lo que se dirige la crítica de Marx. El dominio del

\footnotetext{
42 Un detallado compendio sobre las motivaciones de este "giro» puede encontrarse en A. Wellmer, «Comunicación y emancipación», Isegoría, nº 1, (1990): 15-48.
} 
valor de cambio, afianzado por el proceso de valorización del capital, debe substituirse por la satisfacción de las necesidades humanas reales. La producción por la producción debe dar paso a la producción para el ser humano. En este sentido, la crítica marxiana al carácter instrumental del trabajo en el capitalismo no admite

«la tesis habermasiana de que el concepto de trabajo en Marx es el de techné, o actividad instrumental, sino el de forma específica y fundamental de praxis en el significado antropológico que le da en los Manuscritos de 1844 y reafirma en su definición de El Capital. No se trata, pues, de una relación puramente instrumental, utilitaria, del hombre con la naturaleza, ya que supone necesariamente cierta relación entre los hombres (la que Habermas considera propia de la acción comunicativa, con sus esferas simbólicas, de intersubjetividad y lenguaje) $»^{43}$.

Asimismo, el concepto marcuseano de producción y reproducción engloba también, como en el caso de Marx, la comunicación, la interacción simbólica y otras actividades humanas que trascienden el horizonte del trabajo instrumental ${ }^{44}$. Por esta razón, Marcuse está lejos de postular una «metafísica del trabajo» donde todas las actividades humanas se vean reducidas sin más al Arbeit.

A modo de cierre, no podemos dejar de hacer mención al cuestionamiento de la ontología del trabajo -y de la categoría de trabajo como tal- llevada a cabo recientemente por los críticos alemanes del valor. La trayectoria de la "crítica al trabajo» se remonta a El derecho a la pereza (1883) de Lafargue, al propio Marx, y a diversos sectores del marxismo crítico y autónomo operativos durante el siglo XX (Internacional Situacionista ${ }^{45}$, Po-

\footnotetext{
${ }^{43}$ G.Vargas Lozano, «La persistencia del marxismo (entrevista con Adolfo Sánchez Vázquez)». Revista Internacional de filosofía política, n 7, (1996): 190.

${ }^{44}$ D. Kellner, Herbert Marcuse and the Crisis of Marxism, 83.

${ }^{45}$ El marxismo heterodoxo de la Internacional Situacionista, que insistía tanto en la destrucción de la sociedad del espectáculo (Debord) como en la revolución de la vida cotidiana (Vaneigem), no podía aceptar la ética protestante ni el ascetismo derivado del énfasis filosófico en la categoría ontológica de trabajo. A principios de los años 50 , dejaron constancia de su programa de mínimos en una famosa inscripción en las paredes de París: Ne travaillez jamais.
} 
tere Operaio y Autonomia Operaia ${ }^{46}$, etc.). Es importante desglosar dentro de este variopinto conglomerado las críticas dirigidas al trabajo en-sí, a ciertos modos de trabajo (asalariado, enajenado...) o al carácter obligatorio del mismo. La Wertkritik alemana, encabezada por Robert Kurz, se sirvió de los elementos más sustanciales de las corrientes precedentes para elaborar una aguda crítica de signo renovado que plasmó en una suerte de declaración de intenciones, el Manifiesto contra el trabajo (1999) ${ }^{47}$. Discrepando de las interpretaciones al uso que tienden a fragmentar la obra teórica de Marx entre su período juvenil (filosófico) y de madurez (científico), Kurz propone una original diferenciación entre el Marx «exotérico» y el «esotérico». Con el primer término se refiere al Marx positivista,

«el descendiente y disidente del liberalismo, el político socialista de su tiempo y mentor del movimiento obrero, que nunca quiso otra cosa que derechos civiles y un 'salario justo para una jornada de trabajo justa'. Ese Marx $\mathrm{n}^{\circ} 1$ parece adoptar una perspectiva ontológica del trabajo, incluyendo la ética protestante correspondiente, reivindicar la 'plusvalía no pagada' y querer substituir la jurídica 'propiedad privada de los medios de producción' por la propiedad estatal» ${ }^{48}$.

Complementariamente a este Marx, que asume de un modo un tanto ingenuo los ideales filosóficos de la Ilustración, hay también otro Marx, «esotérico» y negativo, el crítico de la «forma valor», del fetichismo de la mercancía y del «trabajo abstracto».

\footnotetext{
${ }^{46}$ Las tendencias autonomistas italianas tuvieron cierta incidencia en las fábricas de Italia durante la década de los 70 . Entre las estrategias para entorpecer el desarrollo normal de las fuerzas productivas se incluían el absentismo laboral y los actos de sabotaje dirigidos al aparato de producción.

${ }^{47}$ Una crítica al argumentario del Manifiesto y, en general, a los planteamientos de los «críticos del valor»- principalmente dirigida a R. Kurz y A. Jappe- se encuentra en J. Semprún, El fantasma de la teoría. Notas sobre el Manifiesto contra el trabajo (Bilbao: DDT, 2004).

${ }^{48}$ R. Kurz, «Der doppelte Marx», www.exit-online/textanz1.php?tabelle=autoren\&index $=$ 24\&posnr=50 Véase también, R. Kurz, «Der doppelte Marx. Max als immanenter Modernisierungstheoretiker und als Kritiker der Basisstruktur moderner warenproduzierender Systeme», en H. Eindam, W. Schmied-Kowarzik (ed.), Kritische Philosophie gesellschaftlicher Praxis. (Würzburg: Königshausen und Neumann, 1995), 151-166.
} 
«El Marx $n^{\circ} 2$ orienta su análisis teórico no hacia los intereses sociales inmanentes al sistema, sino hacia el carácter histórico del propio sistema. El problema aquí ya no es la 'plusvalía no pagada', o el poder jurídico de disposición de la propiedad privada, sino la propia forma social del valor, que es común a las clases en lucha y la primera causa del antagonismo de sus intereses ${ }^{49}$

Ni el Marx «exotérico» corresponde al Marx «maduro» ni el Marx «esotérico» al «joven Marx». Una y otra tendencia están presente en sendas fases de su vida. Así, en los Manuscritos de economía y filosofía también son visibles los dos Marx a los que alude Kurz. En la crítica del carácter alienado del trabajo abstracto prevalecería la tendencia «esotérica», mientras que en el desarrollo de una ontología general del trabajo, donde este aparece como la esencia probatoria del ser humano, se divisaría la herencia ilustrada y la ética protestante característica del Marx «exotérico». Esta última tendencia tuvo una valiosa función en el desarrollo de la lucha de clases del movimiento obrero. Sin embargo, la superación del modelo social basado en la formavalor no puede lograrse con la mera reivindicación de un salario justo, de una reducción de la jornada laboral o de una colectivización de los medios privados de producción. Por lo demás, la aclaración teórica de los trascendentales ontológicos del trabajo no desempeña a día de hoy la función crítica que pudo tener antaño ${ }^{50}$. No así la crítica al trabajo abstracto y al proceso de cosificación, que mantienen plenamente su vigencia para el contexto histórico actual.

\footnotetext{
${ }^{49}$ www.exit-online/textanz1.php?tabelle $=$ autoren\&index $=24 \&$ posnr $=50$

${ }^{50}$ La evolución de las propias dinámicas del capitalismo, en especial la transformación y la enorme diversificación de las formas de organización social del trabajo, debería llevar a un profundo replanteamiento en la aclaración de los trascendentales ontológicos del trabajo, si es que tal aclaración ontológica, basada en gran parte en un modelo hegeliano ya caído en desuso, debe seguir siendo de interés para nosotros y nosotras.
} 


\section{REFERENCIAS BIBLIOGRÁFICAS}

Althusser, L. La revolución teórica de Marx. México: Siglo XXI, 2004.

Feuerbach, L. La esencia del cristianismo. Barcelona: Círculo de Lectores, 1996.

Habermas, J. et al. Conversaciones con Herbert Marcuse. Barcelona: Gedisa, 1980.

Kellner, D. Herbert Marcuse and the Crisis of Marxism. Los Angeles: University of California Press, 1984.

Kurz, R. «Der doppelte Marx. Max als immanenter Modernisierungstheoretiker und als Kritiker der Basisstruktur moderner warenproduzierender Systeme», en H. Eindam, W. Schmied-Kowarzik (ed.), Kritische Philosophie gesellschaftlicher Praxis. Würzburg: Königshausen und Neumann, 1995, pp. 151-166.

McCarthy, T. «Heidegger y la teoría crítica: el primer encuentro», en Ideales e ilusiones: reconstrucción y deconstrucción en la teoría crítica contemporánea. Madrid:Tecnos, 1992, 92-106.

Marcuse, H. Schriften Vol. 1. Frankfurt am Main: Suhrkamp, 1978.

.Entre hermenéutica y teoría crítica. Artículos 1929-1931. Barcelona: Herder, 2011.

. Sobre Marx y Heidegger: escritos filosóficos (1932-1933). edición, traducción e introducción de José Manuel Romero Cuevas. Madrid: Biblioteca Nueva, 2016.

Marx, K. Manuscritos de economía y filosofía. Alianza: Madrid, 2001.

.La ideología alemana (I) y otros escritos filosóficos. Buenos Aires: Losada, 2010.

Romero, J. M. (ed.). H. Marcuse y los orígenes de la teoría crítica. Madrid: Plaza y Valdés, 2010.

SánchezVázquez, A. El joven Marx. Los Manuscritos de 1844. México: UNAM, 2003. 
Steigerwald, R. Herbert Marcuses dritter Weg. Köln: Pahl-Rugenstein, 1969.

Vargas Lozano, G. «La persistencia del marxismo (entrevista con Adolfo Sánchez Vázquez)», en Revista Internacional de filosofía política, nº 7,1996.

Wolin, R. «Herbert Marcuse: del marxismo existencial al heideggerianismo de izquierdas», en Los hijos de Heidegger. Madrid: Cátedra, 2003, 201251. 